\title{
Ensino e Aprendizagem de Biologia no Ensino Médio através da Informática Educativa
}

\author{
Maicon da Silva Adolfo' ${ }^{1}$, David Machado ${ }^{1}$, Mariusa Warpechowski ${ }^{1}$ \\ ${ }^{1}$ Centro Universitário Cenecista de Osório - (UNICNEC) - Osório - RS - Brasil \\ Curso de Licenciatura em Informática (UNICNEC) \\ maicon.adolfo@gmail.com, david.machado.mv@hotmail.com, \\ mariusaw@gmail.com
}

\begin{abstract}
This work aimed to verify the impact of the use of information and communication technologies (ICT) in the teaching and learning process of biology in high school. For this purpose, a case study was carried out in two high school classes of a state school, where both classes had classes with and without the use of ICTs and underwent an identical evaluation process in order to verify students' performance. The analysis of the results showed that for the target public in question, the use of ICT had a positive impact, since the students who used the ICT obtained a superior performance to the students who did not use.
\end{abstract}

Resumo. Este trabalho teve como objetivo verificar o impacto do uso das tecnologias de informação e comunicação (TIC) no processo de ensino e aprendizagem de Biologia no ensino médio. Para isso foi realizado um estudo de caso em duas turmas do ensino médio de uma escola estadual, onde ambas as turmas tiveram aula com e sem o uso das TIC e passaram por um processo de avaliação idêntico a fim de verificar o desempenho dos alunos. A análise dos resultados mostrou que, para o público alvo em questão, o uso das TIC teve um impacto positivo, pois os alunos que utilizaram as TIC obtiveram um desempenho superior aos alunos que não utilizaram.

\section{Introdução}

A tecnologia vem abrindo e proporcionando diferentes possibilidades no cenário educacional. Por sua vez vem sendo utilizada como ferramenta de ensino e aprendizagem aumentando assim, sua participação no meio educacional e social. Há pouco tempo atrás se fazia necessário justificar a introdução das tecnologias no contexto educacional, hoje já se faz necessário qualificar a sua utilização. Mas mesmo assim, as tecnologias não são muito utilizadas no contexto educacional. Dessa maneira, este trabalho propôs a utilização de recursos tecnológicos no processo de ensino e aprendizagem da Biologia a fim de verificar o impacto sobre o aprendizado dos alunos.

Para atingir esse objetivo, foi realizado um estudo de caso em duas turmas do $2^{\circ}$ ano do Ensino Médio, de uma escola estadual de Ensino Médio no Litoral Norte do Rio Grande do Sul. Para ambas as turmas foram ensinados dois diferentes conteúdos, sendo que em um dos momentos foi com o uso de tecnologia e em outro momento foi sem uso de tecnologia. A partir disto, foi realizado um estudo comparativo do desempenho dos 
alunos levando em consideração a utilização e a não utilização dos recursos tecnológicos.

Através do estudo realizado neste trabalho, pode-se perceber que muitos autores defendem tanto o aprendizado tradicional, sem a utilização de tecnologias, quanto a informática educativa, cada um com um ponto de vista e cada um em seu tempo, criando assim conflitos entre autores. Isso evidencia a importância da presente pesquisa.

A justificativa para esta pesquisa se baseia no que é vivenciado hoje em dia, onde existem crianças e adolescentes que utilizam celulares, tablet, computadores, com muita facilidade, pois além de terem facilidade para o uso destas tecnologias, é algo que elas gostam muito. Então pretende-se descobrir se essas tecnologias, tão presentes na vida dos adolescentes, podem trazer algum benefício para a aprendizagem quando aplicadas na escola. Visto que nos dias de hoje vemos poucos trabalhos realizados na região onde vivemos e também pelo incrível número de alunos que reprovam nas disciplinas da Área da Natureza que englobam Física, Química e Biologia.

O artigo está estruturado da seguinte maneira: na Seção 2 é apresentada a Informática Educativa e na Seção 3 são descritas as relações da Informática Educativa no processo de ensino e aprendizagem de Biologia. A Seção 4 apresenta os caminhos percorridos para a realização da pesquisa, enquanto na Seção 5 são analisados os resultados obtidos com a realização da pesquisa e finalmente a Seção 6 traz algumas considerações finais.

\section{Informática Educativa}

A Informática Educativa na escola facilita o entendimento do conteúdo pelos alunos. Segundo Rocha (2008), a Informática Educativa privilegia a utilização do computador como ferramenta pedagógica que auxilia no processo de construção do conhecimento. Dessa maneira, o computador é um meio e não um fim, devendo ser usado considerando o desenvolvimento dos componentes curriculares. Nesse sentido, o computador transforma-se em um poderoso recurso de suporte à aprendizagem, com inúmeras possibilidades pedagógicas, desde que haja uma reformulação no currículo, que se criem novos modelos metodológicos e didáticos, e principalmente que se repense qual o verdadeiro significado da aprendizagem, para que o computador não se torne mais um adereço travestido de modernidade (ROCHA, 2008).

O professor cria situações em que o aluno seja deparado com problemas, que o façam utilizar a ferramenta de maneira correta. Desta forma, a informática facilita a construção do conhecimento, pois possibilita a aplicação de diferentes metodologias e formas de conduzir o processo de ensino e aprendizagem. Na visão de Dante (1991), "[...] a dissolução dos problemas auxilia a desenvolver no aluno a habilidade de elaborar raciocínio lógico e fazer uso inteligente e eficaz dos recursos disponíveis, para que ele possa propor boas soluções às questões que surgem em seu dia-a-dia, na escola ou fora dela.".

Utilizando corretamente as tecnologias, os alunos podem realizar tarefas, classificadas pelo professor, que simulem o seu dia-a-dia dentro e fora da escola. Assim, trabalha o desenvolvimento das habilidades do aluno em perceber situações nas quais poderá utilizar os meios tecnológicos fora do âmbito escolar. Smole e Diniz (2007) 
compartilham da mesma ideia, afirmando que "o desafio é colocar todo potencial dessa tecnologia a serviço do aperfeiçoamento do processo educacional, aliando-a ao projeto da escola com o objetivo de preparar o futuro cidadão.”. Procura-se desenvolver, nos alunos jovens, a percepção do uso das ferramentas tecnológicas no dia-a-dia, no trabalho, no cotidiano podendo fazer uma ligação entre as aulas e a vida do sujeito, capacitando o aluno para realizar tarefas utilizando as ferramentas tecnológicas.

Segundo Lopes (2002), com o passar do tempo, algumas escolas, percebendo o potencial das TIC, introduziram a Informática educativa, que, além de promover o contato com o computador, tinha como objetivo a utilização dessa ferramenta como instrumento de apoio às disciplinas e aos conteúdos lecionados.

É necessário procurar realizar atividades no laboratório para se familiarizar com as diferentes ferramentas e procurando crescer como profissional, utilizando a informática educativa como uma ferramenta de aprendizado agregando valores a suas aulas e assim incentivando o aprendizado dos alunos. Para Lopes (2002), se um dos objetivos do uso do computador no ensino for o de ser um agente transformador, o professor deve ser capacitado para assumir o papel de facilitador da construção do conhecimento pelo aluno e não um mero transmissor de informações.

A tecnologia nos dias de hoje está cada dia se tornando mais utilizável no âmbito educacional, e na difusão de conhecimento e informações, fazendo assim nascer um novo paradigma que é o "aprender com a tecnologia". Como destaca Nogueira (1993, p.23), "[...] a utilização dessas novas tecnologias não representa somente um avanço nos recursos educacionais, mas um caminho para a mudança desse paradigma educacional", sendo assim já é necessária a busca por novas abordagens nos processos de ensino e aprendizagem. Essas inovações tecnológicas para alguns autores contemporâneos colocam em dúvida o ensino tradicional vigente nas diretrizes aplicado ainda hoje na maioria das escolas públicas no Brasil.

Carvalho (2006) observa que “[...] o ensino está reduzido à transmissão de conceitos prontos e, a escola tem outro papel, que é o de dotar as pessoas de condições teóricas e práticas para que elas utilizem, transformem e compreendam o mundo da forma mais responsável possível". Sendo assim, podemos observar que a utilização das mídias no cotidiano escolar induz o professor a trabalhar de maneira construtivista, exercendo um papel de mediador de conhecimento.

Na mesma reflexão, Leite (2008) enfatiza que o verdadeiro educador é aquele que sabe conduzir seu aluno na busca e no acesso à informação necessária de modo que possa orientá-lo no processo da construção do conhecimento, interagindo com o seu aluno enquanto ser humano que tem sensibilidade para perceber e atender às suas necessidades e aos interesses pessoais - tarefa que o computador não pode desempenhar bem.

A introdução das tecnologias no contexto educacional oportuniza uma maior participação do professor no ensino e aprendizagem pois, esse professor terá muitas ferramentas como áudio, vídeos, imagens, animações, simulações, gráficos, que tornam a aula mais interativa com o educando, e contribuindo para a assimilação dos conteúdos. Isso é observado também por Chervel, que diz que, "Os conteúdos de ensino são impostos como tais à escola pela sociedade que a rodeia e pela cultura na qual se banha. 
$\mathrm{Na}$ opinião comum, a escola ensina as ciências, as quais fizeram suas comprovações em outro local é a essa concepção dos ensinos escolares que está diretamente ligada à imagem que se faz da "pedagogia" cuja tarefa consiste em arranjar os métodos de modo que eles permitam que os alunos assimilem o mais rápido e o melhor possível a maior porção possível da ciência referida (CHERVEL, 1990, p. 180 - 181).”.

Vendo essa visão que Chervel nos dá, podemos considerar que o professor precisa procurar diversificar suas aulas mudando a sua metodologia, visando contemplar o maior número de alunos possíveis e proporcionando a eles uma mediação de conhecimento vasta para que os próprios educandos descubram o método de aprendizagem que melhor se adapte e que mais assimile o conteúdo.

Como podemos ver, a capacitação é importante para muitos autores como Lopes, Smole e Diniz, logo precisamos de mais capacitação na área de informática educativa, visando melhorar o uso das ferramentas tecnológicas, e que as mesmas sejam utilizadas de maneira correta, buscando o melhor rendimento, para alunos e para professores.

\section{Informática Educativa no Ensino da Biologia}

A área de Ciência da Natureza possui um percentual de reprovação considerável no Ensino Médio, e com a imposição da quantidade de conteúdos acaba por aumentar ainda mais os níveis de reprovação e evasão das escolas. Nesta área do conhecimento temos três disciplinas, Física, Química e Biologia, sendo que a disciplina escolhida para o presente estudo foi a Biologia que na escola onde foi realizado o estudo de caso é uma das disciplinas que mais reprova.

O mesmo ocorre no Ensino Médio politécnico por ter a Biologia um conteúdo considerado complicado de se compreender e de grande importância para o desenvolvimento do aluno. Observando os dados do Programa Dinheiro Direto na Escola (PDDE) do ano de 2013, verifica-se taxas de reprovação da Biologia, superior à média brasileira como mostra a Tabela 1 .

Tabela 1. Porcentagem de reprovação em Biologia

\begin{tabular}{|l|l|l|l|l|l|}
\hline Série/Ano & \multicolumn{1}{|c|}{ Horário } & \multicolumn{1}{|c|}{ Turma(s) } & Disciplina(s) & $\begin{array}{c}\text { Taxa de } \\
\text { Reprovação da } \\
\text { Disciplina (em \%) }\end{array}$ & $\begin{array}{c}\text { Taxa de } \\
\text { Reprovação do } \\
\text { Brasil (em \%) }\end{array}$ \\
\hline $2^{\mathrm{a}}$ série & $13: 00-18: 10$ & 23 Politécnico & Biologia & $24 \%$ & $12,5 \%$ \\
\hline $2^{\mathrm{a}}$ série & $13: 00-18: 10$ & 24 Politécnico & Biologia & $19 \%$ & $12,5 \%$ \\
\hline $2^{\mathrm{a}}$ série & $18: 30-22: 30$ & 25 Politécnico & Biologia & $17 \%$ & $12,5 \%$ \\
\hline
\end{tabular}

Fonte:PDDE Interativo ano 2013.

Borges e Lima (2007) chamam a atenção para a organização do ensino de Biologia no Brasil, que, ainda hoje, privilegia o estudo de conceitos, linguagens e metodologias desse campo de conhecimento, tornando a aprendizagem pouco eficiente para a interpretação e intervenção da realidade. Compartillhando da mesma ideia, Krasilchik (2004) também salienta "que o ensino de Biologia nas escolas brasileiras ainda é bastante teórico, prendendo-se a descrição e segmentação dos conteúdos visando apenas à memorização dos mesmos.”. 
VI Congresso Brasileiro de Informática na Educação (CBIE 2017)

Anais do XXIII Workshop de Informática na Escola (WIE 2017)

A partir deste ponto, as TIC podem constituir-se como um elemento na valorização das práticas pedagógicas vivenciadas nas aulas de Biologia, uma vez, que acrescenta maior dinâmica nos processos de ensino e aprendizagem, fornecendo maior acesso a informação e assim dando outra visão dos conteúdos trabalhados. A utilização das TIC na prática pedagógica, oferece a possibilidade de diversificar as aulas. Com o uso da tecnologia, é possivel elaborar métodos que facilitam a apresentação e a explicação dos conteudos, visto que ela dispõe de inúmeros recursos midiáticos como, imagens, vídeos, sons entre outros. O que vai de encontro ao que salienta Moran (1991), "Educar é procurar chegar ao aluno por caminhos possíveis: pela experiência, pela imagem, pelo som, pela representação (dramatizações, simulações), pela multimídia. É partir de onde o aluno está ajudando-o a ir, do concreto para o abstrato, do imediato para o contexto, do vivencial para o intelectual, integrando o sensorial, o emocional e o racional".

Podemos citar alguns trabalhos que abordam a importância e o uso da tecnologia para o ensino da Biologia. Trombetta (2015) apresenta o processo de desenvolvimento do Construto Digital de Aprendizagem (CDA) Zell, que é um jogo educativo para o reforço do ensino de Biologia, mais especificamente o conteúdo "Transporte Celular". O projeto foi produzido pelo laboratório de objetos de aprendizagem da Universidade Feevale em parceria com o Instituto de Ciências da Saúde da própria instituição. O CDA foi aplicado no primeiro semestre de 2015 em quatro turmas da disciplina de biologia célula, que responderam ao questionário aplicado ao termino das sessões, na qual se buscou validar o uso do CDA como apoio à disciplina. Em todos os quesitos avaliados, a aceitação ficou entre $90 \%$ e $100 \%$, o que demonstra que o uso do CDA pode ser efetivo e que sua proposta pode auxiliar no processo de ensino e aprendizagem de biologia celular, envolvendo o tema transporte celular. A abordagem do conteúdo de forma menos textual agradou e atraiu os alunos da disciplina de biologia celular. Da mesma forma, no que diz respeito ao visual do jogo e sons, a receptividade dos alunos no teste foi excelente e as cores em muitas partes do jogo, segue o mesmo padrão utilizado nos materiais didáticos.

Pereira (2006) realizou um trabalho que faz uma introdução à disciplina Vida Artificial e algumas implicações na pesquisa em ciências. Também exoste o ambiente de nonimado de AVITAE, que pode ser entendido como um ambiente de modelagem computacional que incorpora algumas características de vida artificial, permitindo ao professor de biologia criar situações de ensino-aprendizagem baseados em exploração.

O uso das TIC no contexto de formação do licenciado em Ciências é pesquisado por Lima (2012). A autora buscou analisar as relações estabelecidas entre os conhecimentos prévios e as propostas de ação pedagógica de licenciandos na área de Ciências concernentes ao uso das DIC na escola. Foi realizado um estudo de caso, junto a licenciandos das áreas de Ciências Biológicas e Física, no semestre 2011-2, onde foi constatado que os licenciandos apresentam uma visão aplicacionista do uso das TDIC nas aulas de Ciências, com possibilidades de mudança nos casos em que se colocam a favor da construção do conhecimento a partir da reflexão (LIMA, 2012).

Da mesma forma, nos Parâmetros Curriculares Nacionais do Ensino Médio, é citado que o ensino de Biologia "se volte ao desenvolvimento de competências que permitam ao aluno lidar com as informações, compreendê-las, elaborá-las, refutá-las, 
VI Congresso Brasileiro de Informática na Educação (CBIE 2017)

Anais do XXIII Workshop de Informática na Escola (WIE 2017)

quando for o caso, enfim compreender o mundo e nele agir com autonomia, fazendo uso dos conhecimentos adquiridos da Biologia e da tecnologia." (BRASIL, 1999, p. 225).

Importante destacar que as TIC servem apenas de suporte técnico para as aulas e não como meio de disseminar o conhecimento da Biologia como afirma Leite (2008), "as TIC são recursos importantes para disseminar o conhecimento e apoiar os estudantes em sua evolução. Quando empregadas no ensino da Biologia, auxiliam os alunos no entendimento dos conteúdos, na experimentação de algumas atividades e na possibilidade de interação com seres e estruturas raras ou microscópicas, que de outra forma não poderiam ser visualizadas".

\section{Metodologia}

Este trabalho foi desenvolvido através de estudo de caso e do método comparativo em uma escola de ensino médio. A execução da pesquisa iniciou com uma observação da escola que contava com uma boa infraestrutura em relação a salas, banheiros e refeitório. O laboratório de informática tinha 12 computadores desktop, 32 netbooks, 1 projetor e ar-condicionado. $\mathrm{O}$ ambiente escolar possuía internet sem fio, que podia ser utilizada nos computadores da escola, bem como nos aparelhos pessoais. Os computadores desktop tinham sistema operacional Linux educacional 3.0 e Windows 7, enquanto os netbooks possuíam o Xubunto. Apesar dessa tecnologia estar disponível, os professores não faziam uso dela como apoio ao processo de ensino e aprendizagem.

Verificou-se que a escola tinha em torno de 1000 alunos, que se distribuíam pelos turnos da manhã, tarde e noite. $\mathrm{O}$ público alvo do presente trabalho foram duas turmas do $2^{\circ}$ ano do Ensino Médio, a Turma 25, constituída por 23 alunos, e, a Turma $25 \mathrm{~A}$, composta por 16 alunos. O método avaliativo da escola era qualitativo, onde o objetivo dos alunos é alcançar os seguintes conceitos, Construção Satisfatória da Aprendizagem (CSA), Construção Parcial da Aprendizagem (CPA) e Construção Restrita da Aprendizagem (CRA).

Após as observações foram planejadas as aulas, juntamente com a professora titular da turma, visando abordar os conteúdos de Nutrição e Sistema Digestório. O conteúdo de Nutrição foi trabalhado em dois momentos, o primeiro momento caracterizou-se por não fazer uso da tecnologia, que foi aplicado à Turma $25 \mathrm{~A}$, e, no outro momento, com o uso da tecnologia, sendo aplicado à Turma 25. Da mesma maneira aconteceu para o conteúdo de Sistema Digestório, onde primeiramente foram utilizadas as TIC, para a turma $25 \mathrm{~A}$, e, para a turma 25 não foram utilizadas tecnologias. Neste trabalho o uso das TIC compreendeu a utilização dos seguintes recursos tecnológicos: imagens digitais, simulações, vídeos, pesquisa na Internet e softwares de apresentação de slides.

Nas aulas de Nutrição, para a turma 25A foi apresentado o conteúdo utilizando o quadro branco e livro, e foi solicitado que os alunos fizessem uma atividade, que compreendia a criação de um folder informativo sobre Nutrição. Para a realização desta atividade, os alunos utilizaram livros, revistas e cadernos para a pesquisa, e papel, cartolina, lápis e caneta para a confecção do folder. Na aula de Nutrição para a turma 25, a professora utilizou apresentação de slides, imagens digitais, vídeos e simulações, enquanto os alunos utilizaram pesquisa na internet, imagens digitais, e software de apresentação de slides para a confecção do folder. 
Para avaliar o aprendizado dos alunos em relação ao conteúdo de Nutrição, foi realizada uma avaliação para ambas as turmas. A avaliação compreendia 20 questões, sendo elas, 5 do tipo objetiva simples, 5 objetivas compostas, ambas demandavam justificativa para as respostas selecionadas, 8 questões descritivas e duas questões envolviam cálculos.

O conteúdo de Sistema Digestório foi trabalhado com o uso de TIC na turma $25 \mathrm{~A}$ e sem o uso de TIC na turma 25. Ao final das aulas também foi realizada uma avaliação com o mesmo formato da avaliação sobre Nutrição. As avaliações realizadas foram idênticas para ambas as turmas visando efetuar um comparativo do desempenho dos alunos ao usar tecnologia e ao não usar tecnologia.

\section{Resultados}

Após a aplicação das aulas e das avaliações, foram analisados os resultados, tanto do desempenho dos alunos nas atividades realizadas durante as aulas como na avaliação. Para verificar o desempenho dos alunos na realização das atividades foi solicitado que a professora relatasse como haviam sido as aulas. $\mathrm{O}$ primeiro relato da professora foi " $\mathrm{O}$ uso do recuso digital na aula de Biologia foi de extrema importância, pois foi notório o envolvimento dos alunos com o trabalho sobre nutrição e os folders foram desenvolvidos com muita motivação". A professora ainda destaca que nas aulas em que não houve utilização de TIC, os alunos demonstravam uma certa "preguiça" em realizar as atividades, e ela teve que motivar e solicitar que dessem continuidade na atividade várias vezes, o que ocasionou uma maior demora na realização das atividades por parte dos alunos, tanto na turma 25A, que trabalhou o conteúdo de Nutrição, quanto na turma 25 que trabalhou o conteúdo de Sistema Digestório.

Ainda sobre o relato da professora, ela disse que mesmo os alunos não sabendo utilizar as tecnologias, eles não demoraram para realizar as atividades, ou seja, estavam tão motivados que realizaram as atividades e aprenderam a trabalhar com ferramentas as quais não conheciam, sem precisar que alguém os ensinasse.

Verificou-se também que os alunos da turma 25 que haviam utilizado TIC nas aulas de Nutrição solicitaram que a aula sobre o Sistema Digestório também fosse no laboratório de informática. Como diz Bielschowski (2009), "é importante analisar o impacto do uso de TICs no desempenho escolar com suas várias componentes, entre elas o desenvolvimento da autonomia e criatividade dos estudantes.", portanto, os resultados em relação aos depoimentos da professora, mostram que as TIC fizeram diferença na aprendizagem dos alunos.

A análise sobre o desempenho dos alunos nas avaliações foi feita comparando o desempenho da turma que usou TIC com a turma que não usou TIC. O Gráfico 1 demonstra que a turma 25, com o uso das TIC no conteúdo de Nutrição, obteve um resultado satisfatório, com o maior número de alunos atingindo conceito CSA. 


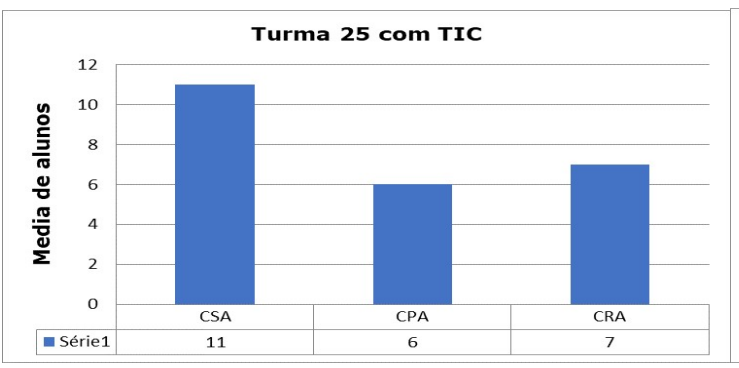

Gráfico 1. Desempenho da Turma 25 com TIC

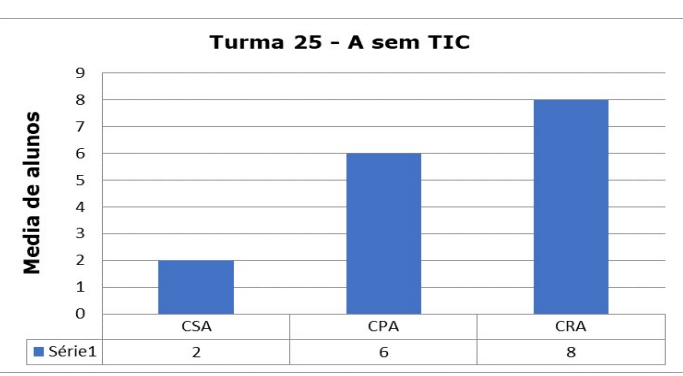

Gráfico 2. Desempenho da Turma 25A sem TIC

O Gráfico 2 mostra o desempenho da turma 25A no conteúdo de Nutrição, sem o uso de TIC. Pode-se observar que existe um maior número de alunos com conceito CRA, e comparando com o desempenho da turma 25, nota-se que o uso das TIC foi relevante no processo de ensino e aprendizagem. Como disse Moran (1991), "Educar é procurar chegar ao aluno por caminhos possíveis", e utilizando as TIC podemos chegar ao aluno com podemos ver no Gráfico 1 e 2 .

As turmas 25 e 25A foram avaliadas em relação ao aprendizado sobre o Sistema Digestório, e os resultados dessas avaliações são mostradas no Gráfico 3 e 4 . No Gráfico 3 podemos ver que a turma $25 \mathrm{~A}$, agora utilizando as TIC, teve um rendimento melhor que no conteúdo de Nutrição. Os alunos da turma 25 relataram que ao usarem as imagens digitais e verem as animações mostradas pela professora, entenderam facilmente como funciona o Sistema Digestório, "bem melhor do que a imagem estática no livro", disse um dos alunos. O que vai de encontro ao que diz Leite (2008), que, "Quando empregadas no ensino da Biologia, auxiliam os alunos no entendimento dos conteúdos, na experimentação de algumas atividades e na possibilidade de interação com seres e estruturas raras ou microscópicas, que de outra forma não poderiam ser visualizadas.".

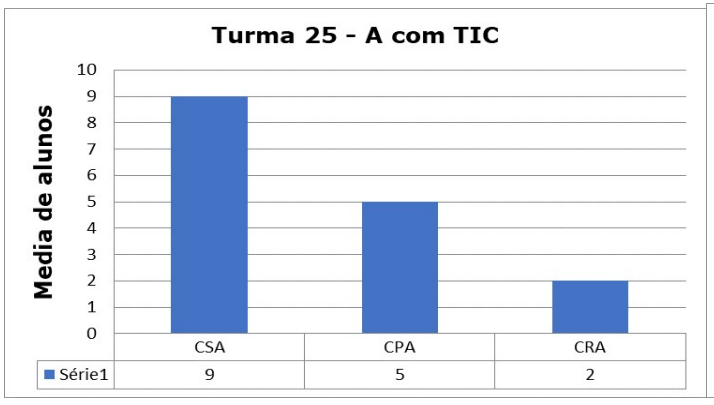

Gráfico 3. Desempenho da Turma 25A com TIC

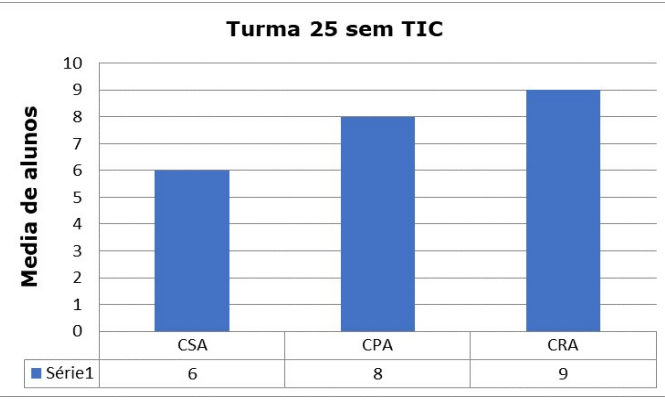

Gráfico 4. Desempenho da Turma 25 sem TIC

Agora com a turma 25 sem a utilização das TIC temos uma considerável diferença nos resultados tendo mais alunos com CPA e CRA do que a turma 25A. Após estes estudos e estas análises podemos perceber que o processo de ensino e aprendizagem na escola, está mais direcionado a transmitir os conceitos já existentes mas como Carvalho (2006) observa que "O ensino está reduzido à transmissão de conceitos prontos e, a escola tem outro papel, que é o de dotar as pessoas de condições teóricas e práticas para que elas utilizem, transforme e compreenda o mundo da forma mais responsável possível.”.

Com base nesses resultados, pode se dizer que as aulas ministradas nesta pesquisa, não foi apenas para transmitir conceitos prontos e sim foram transformadoras, 
VI Congresso Brasileiro de Informática na Educação (CBIE 2017)

Anais do XXIII Workshop de Informática na Escola (WIE 2017)

com conceitos e com embasamento teórico para que os alunos utilizem o que aprenderam no cotidiano fora da escola.

\section{Considerações Finais}

Durante a realização deste trabalho, procurou-se utilizar ferramentas tecnológicas como vídeos, slides, softwares didáticos, buscando verificar se a utilização das TIC faria alguma diferença no aprendizado de Biologia. Neste estudo de caso, foi analisado o impacto do uso das TIC no ensino de Biologia, levando em consideração as tecnologias tão presentes no cotidiano de grande parte dos estudantes. A introdução das mídias, de acordo com Behrens (2000, p. 15) "podem contribuir ao ser em utilizadas de modo a fornecer instrumentos para que o aluno possa agir e interagir no mundo com critério, ética e visão transformadora".

Apesar da tecnologia não ser uma novidade para os alunos e para os professores, não era vista como ferramenta de aprendizagem, e que após as aulas, pode-se verificar que a utilização das TIC traz um ganho de aprendizado satisfatório para o aluno, e que só pelo fato de ter uma aula diferenciada já prende mais a atenção dos alunos, motivando-os e incentivando-os no processo de construção de conhecimento. Considera-se muito importante o uso dos recursos tecnológicos pelos professores, e que os professores que queiram se atualizar digitalmente precisam de incentivos para formação profissional. Este estudo evidenciou a importância, nos dias de hoje, do uso das tecnologias aplicadas ao ensino de Biologia. Assim sendo, podemos concluir que o não uso das TIC deve ser justificado, visto que este estudo comprovou a importância das TIC no processo de ensino e aprendizagem.

\section{Referências}

Bielschowsky, Carlos Eduardo. "Tecnologia da informação e comunicação das escolas públicas brasileiras: o programa Proinfo Integrado." Revista e-curriculum 5.1 (2009).

Borges, R. M. R; Lima, V. M do R. Tendências Contemporâneas do ensino de Biologia no Brasil . Revista eletrônica de Ensenãnza de lãs Ciências. vol.6, $\mathrm{n}^{\mathrm{o}} 1$. 2007.

Brasil. Secretaria de Educação Fundamental. Parâmetros curriculares nacionais: ensino médio: ciências naturais, matemática e suas tecnologias /Secretaria de Educação Média e Tecnológica. Brasília: MEC / SEF, 1999. 114 p.

Carvalho, A. M. P. Ensino de Ciências : unindo a pesquisa e a prática. São Paulo: Pioneira Thomson Learning, 2006.

Chervel. A. História das disciplinas Escolares: reflexos sobre o campo de pesquisa Teoria \&Educação, Porto Alegre n.2 p. 177 - 229, 1990.

Dante, Luiz Roberto. Didática da resolução de problemas de matemática. 2. Ed. São Paulo: Ática, 1991.

Krasilchik. M. O professor e o currículo das Ciências. São Paulo: Universidade de São Paulo, 2007. Prática de ensino de Biologia. Quatro ed. São Paulo: Universidade de São Paulo, 2004. 
VI Congresso Brasileiro de Informática na Educação (CBIE 2017)

Anais do XXIII Workshop de Informática na Escola (WIE 2017)

Leite, L.S. Mídia e a perspectiva da tecnologia educacional no processo pedagógico contemporâneo. In: FREIRE, W. Tecnologia e Educação : as Mídias na Prática Docente. Rio de Janeiro: Wak Editora, 2008.

Lima, L. de; Ribeiro, J. W.; Costa, M. J. N.; Loureiro, C. . Reflexões sobre o Uso da Tecnologia Digital da Informação e Comunicação na Formação do Licenciando de Ciências. In: WORKSHOP SOBRE INFORMÁTICA NA ESCOLA (WIE), XVIII, 2012, Rio de Janeiro, RJ. Anais... Rio de Janeiro, RJ, p.1-10.

Lopes, José Junioet al. A introdução da informática no ambiente escolar. São Paulo, 2002. Disponível em: http://www.clubedoprofessor.com.br/artigos/artigojunio.pdf. Acessado dia 19 de abril de 2017.

Moran, José Manuel. Como ver televisão. Leitura crítica dos meios de comunicação. São Paulo: Edições Paulinas, 1991.

Nogueira, A.C. Multimídia na construção do conhecimento. "Tecnologia Educacional", 22,39 - 411993.

Pereira, A. S. T. \& Sampaio, F. F. (2006) "Utilização de Vida Artificial no Ensino de Ciências Biológicas com TI“. Anais do Simpósio Brasileiro de Informática na Educação, pp. 1 - 7.

Rocha, Sinara Socorro Duarte. O uso do computador na educação: a informática educativa, 2008. Disponível em: $<$ http://www.espacoacademico.com.br/085/85rocha.htm>. Acesso em: 8 de abril, 2017.

Smole, Kátia Stocco e DINIZ, Maria Ignez. Ler, escrever e resolver problemas . Porto Alegre: Artmed, 2007.

Trombetta, André Benvenuti, et al. "Zell Desenvolvimento do CDA para a disciplina de biologia celular." Anais dos Workshops do Congresso Brasileiro de Informática na Educação. Vol. 4. No. 1. 2015. 